\title{
No Apparent Damage in the Thyroid of Transgenic Mice Expressing Antiapoptotic FLIP
}

\author{
Su He Wang, Patricia Arscott, Peiqing Wu, and James R. Baker, Jr.
}

FLIP is an antiapoptotic protein that has been demonstrated to play an important role in inflammation, cancer, and autoimmune diseases. However, it is not known whether increased expression of FLIP (FLICE inhibitory protein) in thyrocytes would alter the development of the thyroid and/or pathogenesis of thyroiditis. To examine the effects of overexpression of this antiapoptotic molecule on the thyroid, we have developed transgenic mouse lines that specifically express FLIP in thyrocytes. A DNA construct designed with an in-frame coding sequence for the E8 protein, a viral FLIP, was put under the control of the thyroglobulin ( $\mathrm{Tg}$ ) promoter (the Tg-FLIP transgene). In 8 of 12 resultant transgenic mouse lines, FLIP expression in thyrocytes driven by the $\mathrm{Tg}$ promoter was documented, and confirmed at RNA and protein levels. These Tg-FLIP transgenic mice were monitored for 1 year. Throughout the entire observation period, the transgenic mice remained alive and healthy without evidence of thyroid dysfunction. Adult mice were able to breed. Histologic examination of thyroids obtained at various time points did not reveal significant differences between transgenic mice and their control littermates. Therefore, transgenic mice with thyrocyte-specific expression of FLIP have normal thyroid development with no significant changes in thyroid cell death or proliferation.

\section{Introduction}

D ISRUPTION OF THE NORMAL REGULATION of cell death pathways has been implicated in a number of pathologic conditions such as autoimmunity and cancer. There is increasing evidence showing that signal transduction through death receptors, such as Fas or TRAIL, contributes to the development of autoimmune thyroiditis. Recent studies have attempted to define the regulation of receptor-mediated cell death pathways in both normal and diseased thyroid in vitro; however the function of these pathways in vivo is more complex.

Thyroid cells are known to express Fas (1), but the expression of Fas does not necessarily render thyrocytes susceptible to Fas ligand-induced apoptosis because of the existence of certain cellular inhibitors (2). One of these regulators of death receptor-mediated apoptosis is FLIP (FLICE inhibitory protein) $(3,4)$. Cross-linking of Fas ligand induces apoptosis through procaspase-8 recruitment to the Fas-mediated death-inducing signaling complex (DISC), where procaspase- 8 is then cleaved to initiate apoptosis. The recruitment of the caspase- 8 inhibitor FLIP into the DISC prevents the cleavage of procaspase- 8 , resulting in reduced apoptotic activity $(3,4)$.

There are several publications indicating that altered FLIP concentrations are found in inflammation and autoimmune diseases, including rheumatoid arthritis and experimental autoimmune thyroiditis (5-9). A study by Wei et al. (8) demonstrated that the upregulation of FLIP by inflammatory cells blocks Fas-mediated apoptosis, contributing to chronic inflammation. In contrast, increased FLIP expression by thyrocytes in resolving granulomatous experimental autoimmune thyroiditis (G-EAT) protects thyrocytes from apoptosis. This study further suggests that increased FLIP and decreased Fas ligand expression by inflammatory cells might block apoptosis of $\mathrm{CD}^{+} \mathrm{T}$ cells, resulting in chronic granulomatous thyroiditis (9). Overexpression of FLIP has also been found to exacerbate experimental autoimmune encephalomyelitis and multiple sclerosis (10-13). This suggests an important immunoregulatory role for FLIP in autoimmunity.

To determine whether the overexpression of FLIP in thyrocytes would have any impact on thyroid development or the pathogenesis of thyroid diseases, we developed transgenic mice that specifically expressed FLIP in the thyroid. This was accomplished by a transgene in which the promoter for thyroglobulin $(\mathrm{Tg})$, a thyroid-specific protein, drove the expression of the E8 protein, a viral FLIP. The expression of E8 has been shown to block apoptosis induced through several death domain-containing receptors, including TNF-R, Fas, and TRAIL receptors $(14,15)$. In this report we describe the construction of this transgene and the initial characterization of Tg-FLIP transgenic mice. 


\section{Materials and Methods}

\section{The transgene construct}

The plasmid Tg-FLIP-myc was constructed from a CMVFLIP plasmid containing a 519-bp insert of the viral FLIP in pCDNA3.1(-)/Myc-HisA (16) as a generous gift from Dr. Claudius Vincenz (University of Michigan, Ann Arbor, MI). The rat $\mathrm{Tg}$ promoter region (17) was generated by polymerase chain reaction (PCR) from rat tail DNA to include $\mathrm{XbaI}$ and XhoI restriction enzyme sites: the $5^{\prime}$ primer: 5'ATATAC TTATCT AGACTG CAGACA AGCAGG CATGC3' and the 3' primer: 5'-TTAACT ATACTC GAGTAC TCAAAT GATGGG GTAGGA G-3'. The resulting 889-bp PCR product was cut with $\mathrm{XbaI}$ and $\mathrm{XhoI}$ to create an 869bp insert. The insert was then purified and cloned in-frame at the $5^{\prime}$ end of the open reading frame of the FLIP sequence in CMV-FLIP. The distance between the start of the TATA box and the start of transcription $(+1)$ is $30 \mathrm{bp}$, and between +1 and the ATG of FLIP is $39 \mathrm{bp}$. Both intervals are the same distances as those in the natural rat Tg gene (Fig. 1). The correct sequence of the $\mathrm{Tg}$ promoter and its insertion site were verified with DNA sequencing by the Core Facility at the University of Michigan.

\section{Transgenic mice and breeding}

To generate Tg-FLIP transgenic mice, the plasmid Tg-FLIP was digested with XbaI and DraIII to create a 2014-bp fragment of transgene, which was gel purified for microinjection (Fig. 1). Microinjection of the Tg-FLIP transgene into eggs from $(\mathrm{C} 57 \mathrm{BL} / 6 \times \mathrm{SJL}) \mathrm{F}_{1} \times(\mathrm{C} 57 \mathrm{BL} / 6 \times \mathrm{SJL}) \mathrm{F}_{1}$ females was performed by the University of Michigan Transgenic Animal Core. Of 81 resultant pups, 12 were identified as positive for Tg-FLIP by PCR (described below). These founder lines were housed in SPF facilities at the University of Michigan and maintained according to UCUCA protocols. Transgene positive mice are currently being crossed into a CBA/J (Jackson Laboratory, Bar Harbor, ME) background for use in mouse models of thyroiditis. Tg-FLIP-positive and $\mathrm{Tg}$ FLIP-negative mice produced from these crosses were used to characterize expression of the transgene further in these lines.

\section{PCR screening}

DNA for transgene screening was performed on tail biopsies of 3-week-old mice. Tail sections were digested overnight with proteinase $\mathrm{K}$, and DNA was then extracted with phenol and chloroform followed by precipitation with ethanol and reconstitution in $200 \mu \mathrm{L}$ of TE buffer. DNA samples from transgenic mice were screened for the presence of the Tg-FLIP transgene by PCR using primers that amplify a $1285 \mathrm{bp}$ sequence between position -660 in the $\mathrm{Tg}$ promoter and the myc tag (Fig. 1): TGP1: 5'-ATATTC TTGCCA CTTCCT GCCC-3' and TGP4: 5'-ATGGTC GACGGC GCTATT CAG-3'. Two microliters of tail DNA were used in a PCR reaction with $1 \times$ Amplitaq buffer containing $1.5 \mathrm{mM}$ $\mathrm{MgCl}_{2}, 0.2 \mathrm{mM}$ dNTPs, $0.3 \mathrm{mM}$ each primer, and 2.5 units Amplitaq DNA polymerase in a volume of $50 \mu \mathrm{L}$. PCR was performed using a Perkin-Elmer 2400 thermocycler with the following program: $94^{\circ} \mathrm{C}$ for 5 minutes; first 10 cycles of denaturation at $94^{\circ} \mathrm{C}$ for 30 seconds, annealing at $64^{\circ} \mathrm{C}$ for 30 seconds, and extension at $72^{\circ} \mathrm{C}$ for 90 seconds; then 25 similar cycles with an extension time of 120 seconds; followed by $72^{\circ} \mathrm{C}$ for 7 minutes and finishing at $4^{\circ} \mathrm{C}$. PCR reaction products were analyzed by electrophoresis on $1.5 \%$ agarose gel. DNA quality was confirmed using primers for rat $\beta$-actin or mouse $\beta$-globin: $\beta$-actin forward: $5^{\prime}$-CACGGC ATTGTA ACCAAC TG-3', $\beta$-actin reverse: $5^{\prime}$-TCTCAG CTGTGG TGGTGA AG-3', $\beta$-globin 1 : 5'-CCAATC TGCTCA CACAGG ATAGAG AGGGCA GG-3', and $\beta$-globin 2: 5'-CCTTGA GGCTGT CCAAGT GATTCA GGCCAT CG-3'. PCR for $\beta$ actin yielded a 402-bp product that was obtained using the same protocol as PCR using the Tg-FLIP primers except for annealing at $62^{\circ} \mathrm{C}$ and extension times of 75 seconds in the first 10 cycles followed by 90 seconds during the final 25 cycles. PCR for $\beta$-globin yielded a 494-bp fragment and was run at $94^{\circ} \mathrm{C}$ for 5 minutes, 35 cycles of $94^{\circ} \mathrm{C}$ for 30 seconds, $62^{\circ} \mathrm{C}$ for 30 seconds, and $72^{\circ} \mathrm{C}$ for 90 seconds. This was followed by $72^{\circ} \mathrm{C}$ for 7 minutes and the process was finishing at $4^{\circ} \mathrm{C}$.

\section{Southern blot}

Ten micrograms of tail DNA of transgenic mice was digested with 30 units of SalI for 6 hours at $37^{\circ} \mathrm{C}$. Tail DNA of negative mouse and tail DNA of negative mouse spiked with 100 copies of the transgene Tg-FLIP plasmid were also included as controls. Digested DNA was run on a $0.8 \%$ agarose/0.5 $\times$ TBE gel overnight at $25 \mathrm{~mA}$. Before transfer, the DNA in the gel was denatured with $0.5 \mathrm{M} \mathrm{NaOH} / 1.5 \mathrm{M}$ $\mathrm{NaCl}$ for 1 hour and neutralized with two changes of $3 \mathrm{M}$ $\mathrm{NaCl} / 0.5 \mathrm{M}$ Tris, $\mathrm{pH} 7.5$ for 45 minutes. DNA was transferred to nitrocellulose membrane by upward capillary electrophoresis in $10 \times$ SSC buffer overnight. After overnight

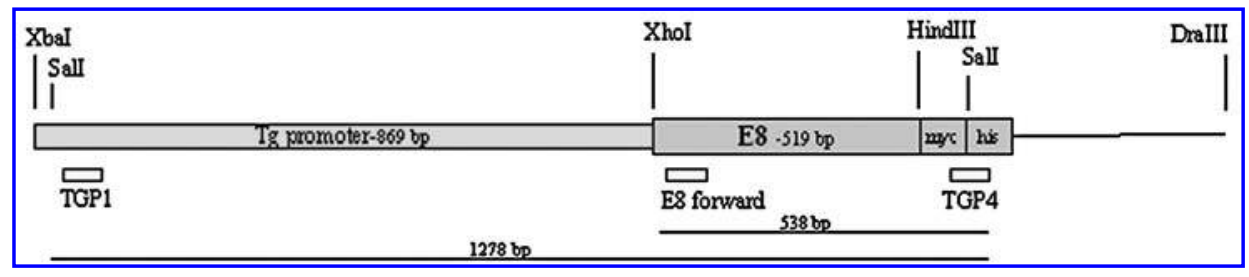

FIG. 1. Schematic diagram of the Tg-FLIP plasmid. The Tg-FLIP transgene in pCDNA3.1(-)/Myc-HisA is depicted showing the relative positions of the rat thyroglobulin $(\mathrm{Tg})$ promoter, the FLIP sequence including the tag sequences for a c-myc peptide and a 6 histidine peptide. Restriction enzyme sites (XbaI and DraIII) used for constructing the transgene as well as those used for Southern blot are shown. The relative positions for annealing of polymerase chain reaction (PCR) primers (TGP1, TGP4 and E8 forward) are also shown. 
transfer, the membrane was rinsed with $2 \times$ SSC. DNA was cross-linked to the membrane using a Stratalinker (Stratagene, La Jolla, CA) at $120,000 \mu \mathrm{J} / \mathrm{cm}^{2}$.

Southern blotting was conducted by first incubating the membrane with $1 \times$ prehybridization solution $(6 \times$ SSC, $10 \times$ Denhardt's, $0.1 \%$ sodium dodecyl sulfate [SDS], $0.5 \mu \mathrm{g} / \mathrm{mL}$ salmon sperm DNA) in a roller bottle for 30 minutes at $65^{\circ} \mathrm{C}$. Tg-FLIP plasmid digested with $\mathrm{XbaI}$ and DraIII was gel purified for use as a probe. Twenty-five nanograms of probe was labeled with $[-\gamma 32 \mathrm{P}] \mathrm{dATP}$ using a Random Primers DNA Labeling System (Invitrogen Life Technologies, (Carlsbad, CA) according to the manufacturer's instructions. The labeled probe was purified using G-50 Sephadex Quick Spin Columns (Roche, Alameda, CA) for radiolabeled DNA purification following manufacturer's instructions. The probe was added to $20 \mathrm{~mL} 1 \times$ prehybridization solution and boiled for 5 minutes. The prehybridization solution was replaced with the boiled probe solution and incubated overnight at $65^{\circ} \mathrm{C}$. This solution was then removed and the blot washed 3 times in $6 \times \mathrm{SSC}$ for 10 minutes at $65^{\circ} \mathrm{C}$, followed by a wash with $2 \times \mathrm{SSC} / 0.5 \%$ SDS for 10 minutes at $65^{\circ} \mathrm{C}$. Bands were visualized by exposing the blot to x-ray film.

\section{Thyroid recovery and morphologic evaluation}

Transgene-positive and transgene-negative mice were humanely sacrificed by an overdose of anesthetic using a protocol approved by our animal use committee. The thyroids from these animals were then dissected and the tissue used in subsequent analyses. For histology, the thyroid glands were removed with part of the trachea still attached. For cryosections tissue was snap-frozen in OCT (Sakura, Finetek, USA, Inc., Torrance, CA) on dry ice, and stored at $-70^{\circ} \mathrm{C}$. For paraffin-embedded sections tissue was fixed in $10 \%$ buffered formalin (Fisher, Middletown, VA). Sections were cut to $5 \mu \mathrm{m}$ and stained with hematoxylin and eosin (H\&E) to examine thyroid structure. For analysis of RNA and proteins, the thyroid glands were separated from the trachea and removed.

\section{RNA isolation and RT-PCR}

Mouse thyroid tissue was added directly to TriZol (Invitrogen Life Technologies), then stored at $-70^{\circ} \mathrm{C}$. Excised thyroid tissue equaled approximately $1-3 \mathrm{mg}$ in weight, so when necessary thyroids from DNA-positive or DNA-negative littermates were combined to provide adequate amounts of RNA for analysis. Small pieces of 7-12 mg of liver tissue or submandibular gland were also collected as control tissue and RNA was isolated in a similar manner. To obtain RNA, the tissue was thawed and homogenized using a micropestle, then RNA isolation was completed according to the vendor's protocol. One microgram of RNA was used in a reverse transcription (RT) reaction with $12.5 \mathrm{ng} / \mu \mathrm{L}$ oligo $(\mathrm{dT})_{18}$ primer in $1 \times$ first strand buffer, $10 \mathrm{mM}$ DTT, $0.5 \mathrm{mM}$ dNTPs, $0.5 \mathrm{U} / \mu \mathrm{L}$ RNase inhibitor (Roche), and with or without $10 \mathrm{U} / \mu \mathrm{L}$ Superscript II reverse transcriptase (Gibco Life Technologies, Gaithersburg, MD) for 1 hour at $42^{\circ} \mathrm{C}$. A duplicate reaction without RT was also run as a negative control. Two microliters of each RT or no RT sample was then used in a PCR reaction with a primer that annealed to the $5^{\prime}$ end of the FLIP transcript (E8 forward) and the TGP4 primer (5'-TGGACG AGGATG AGACCG AG-3') using the same re- action conditions used to screen tail DNA. Amplification of the $\beta$-actin (or $\beta$-globin) sequence was also performed as described above to confirm that the RT reactions had produced good cDNA for PCR. RT-PCR reaction products were visualized on a $1.5 \%$ agarose gel containing ethidium bromide.

\section{Protein isolation and Western blot}

Mouse tissue protein was isolated from TriZol homogenized tissue after extraction of RNA, using the manufacturer's protocol (Invitrogen, Carlsbad, CA). Protein was suspended in $1 \%$ SDS and insoluble material pelleted at $13,000 \mathrm{~g}$ for 10 minutes. Protein concentrations were determined using the BCA Protein Assay Kit (Pierce, Rockford, IL) and at least $10 \mu \mathrm{g}$ of each sample was separated by $15 \%$ sodium dodecyl sulfate-polyacrylamide gel electrophoresis (SDSPAGE) followed by electrophoretic transfer to nitrocellulose membrane. The membrane was subsequently blocked in 5\% milk in phosphate-buffered saline (PBS) with $0.05 \%$ Tween20 (PBS-T). Protein bands corresponding to FLIP-myc/His were identified by Western blot using a mouse monoclonal antibody $(\mathrm{mAb})$ to the c-myc peptide, clone 9E10 (Roche or BACo) at $2 \mu \mathrm{g} / \mathrm{mL}$ diluted in 5\% milk/PBS-T followed by a peroxidase-conjugated anti-mouse immunoglobulin $\mathrm{G}$ (IgG), Fc-specific Ab (Jackson Laboratory) and detected using a chemiluminescent substrate, ECL-Plus (Amersham, Piscataway, NJ). Lysates from COS-1 cells stably transfected with the CMV-FLIP plasmid were used as a positive control for FLIP expression.



FIG. 2. Expression of Tg-FLIP plasmid in the TNT T7 Quick Coupled transcription/translation system (Promega, Madison, WI). One microgram of Tg-FLIP, Tg-Fas, or CMV-FLIP were added to the TNT T7 quick reaction. After the transcription/translation was complete, a 3- $\mu \mathrm{L}$ aliquot of each reaction was separated on a $12 \%$ sodium dodecyl sulfatepolyacrylamide gel electrophoresis (SDS-PAGE) gel. The dried gel was exposed on an X-film at $-70^{\circ} \mathrm{C}$ for 16 hours. The film then was developed. 


\section{Results}

In vitro transcription and translation of Tg-FLIP

The Tg-FLIP plasmid was confirmed to have the correct sequence of the $\mathrm{Tg}$ promoter and insertion site in the vector with sequence analysis. In order to verify the Tg-FLIP construct further, the TNT-coupled transcription/translation system was applied according to manufacturer's protocol (Promega, Madison, WI). Under in vitro transcription/translation conditions, the Tg-FLIP construct expressed the FLIP protein of the predicted size $(22.8 \mathrm{kd})$, which was the same size produced by the CMV-FLIP (Fig. 2). It is obvious that CMV promoter is much more potent than the $\mathrm{Tg}$ promoter. As a negative control, the Tg-Fas construct did not express the same size band.

\section{Screening of $T g-F L I P \times C B A / J$ mice for transgene}

A total of 81 mice were produced from the Tg-FLIP transgene microinjection. Of these, $12 \mathrm{Tg}$-FLIP-positive founder mice were identified (designated numbers $811,813,814,826$, $827,828,833,837,840,842,857$, and 984). The founder mice were bred and crossed with the CBA/J strain to produce TgFLIP transgenic mice. Eleven of the 12 founder mice produced positive progeny, as demonstrated by PCR of tail DNA from litters of founders 826 and 857 (Fig. 3).

\section{Confirmation of transgene insertion by Southern blot}

Southern blots confirmed the presence of the Tg-FLIP transgene in 8 of the founder lines. The number of transgene copies detected in each founder mouse varied (Fig. 4). Four

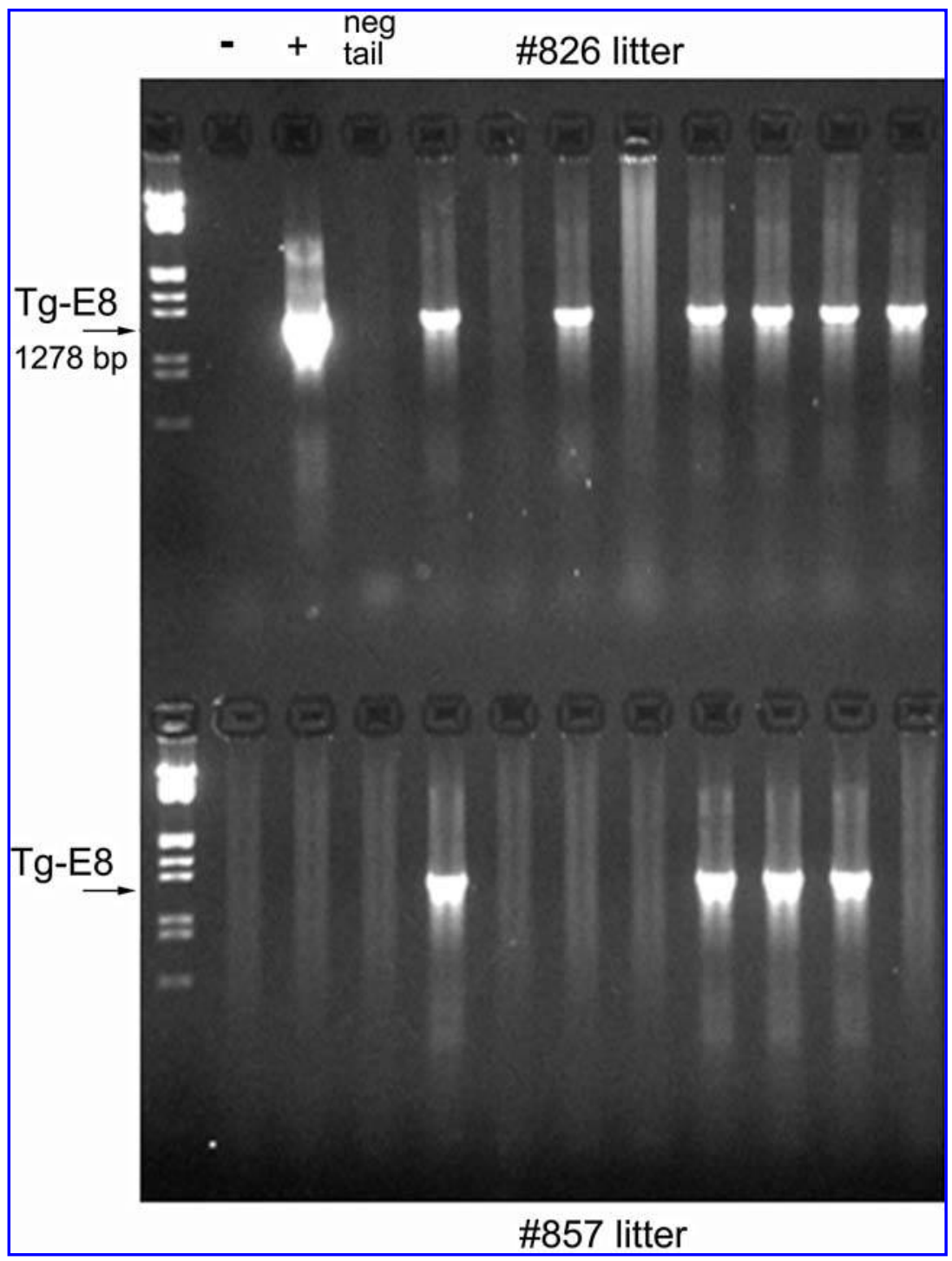

FIG. 3. Polymerase chain reaction (PCR) of mouse tail DNA for Tg-FLIP (Tg-E8) in litters using TGP1 and TGP4 primers. PCR amplification of two different founder lines is shown. An expected band of $1278 \mathrm{bp}$ identified positive and negative littermates. Negative controls included a sample without DNA and a sample with DNA from a negative mouse. Diluted Tg-FLIP plasmid was used as a positive control. 


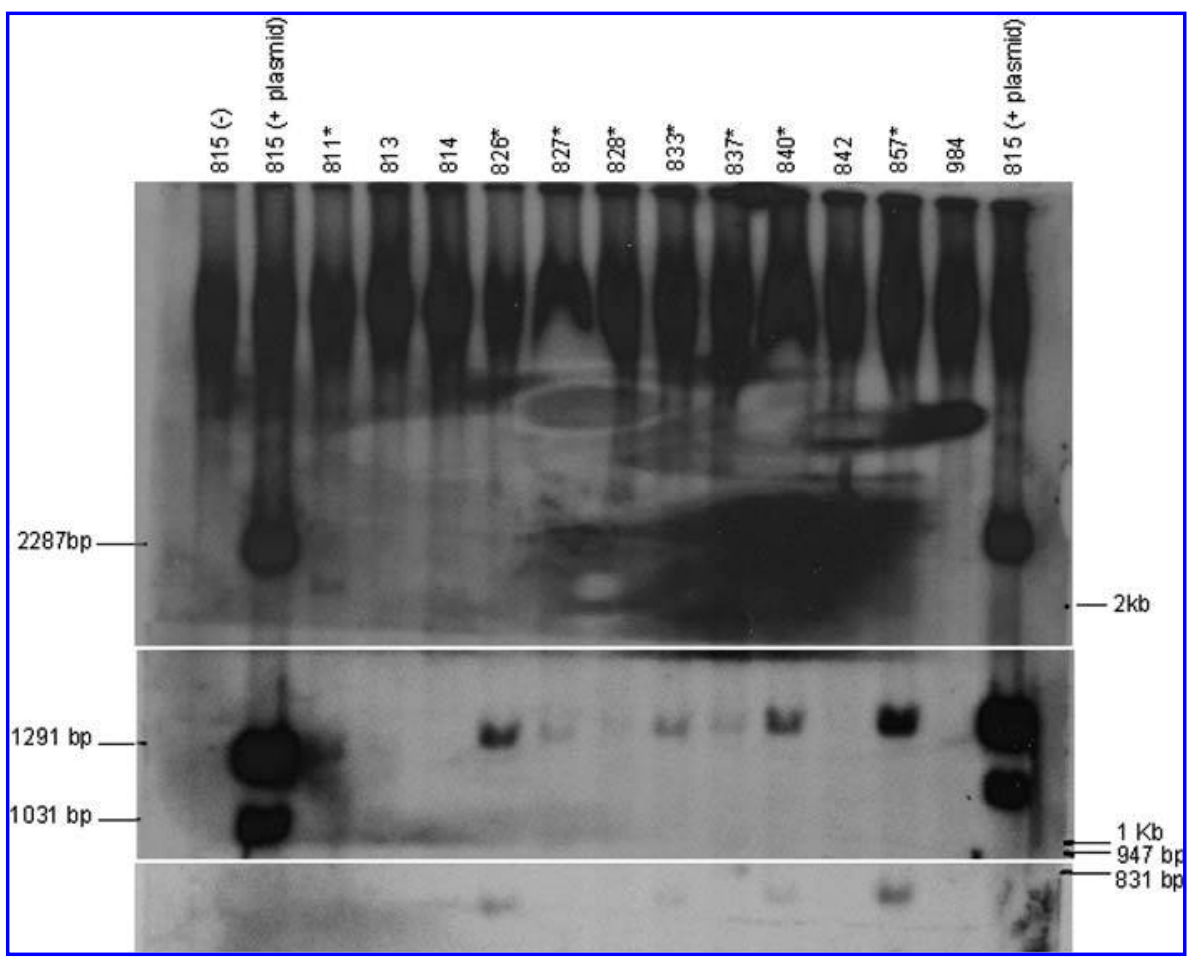

FIG. 4. A Southern blot with DNA from the 12 Tg-FLIP founder mice probed with radiolabeled transgene sequence. The Tg-FLIP transgene is cut twice by SalI producing a major fragment of $1291 \mathrm{bp}$ and two end fragments of $579 \mathrm{bp}$ and $148 \mathrm{bp}$. A 1291-bp band was detected in 8 mice ${ }^{*}$ ). A 727-bp band was also present in 4 mice indicating tandem insertion. The TgFLIP plasmid was included as a positive control and yielded expected bands of 2287, 1291, and $1031 \mathrm{bp}$.

founder lines contained a Southern fragment of $727 \mathrm{bp}$, which indicated the insertion of multiple gene copies into the genome in tandem (numbers 826, 833, 840, and 857). Of these, two lines appeared to contain significantly more copies of the Tg-FLIP transgene as demonstrated by the intensity of both the 1291bp and the 727-bp fragments (numbers 826 and 857).

\section{Detection of mRNA for transgenic FLIP in the thyroids of Tg-FLIP mice}

RT-PCR of RNA extracted from the mouse thyroids demonstrated message for FLIP-myc/His in Tg-FLIP-positive mice, but not in DNA-negative mice, nor in other tissues in the transgene positive mice. A PCR product of $538 \mathrm{bp}$ was
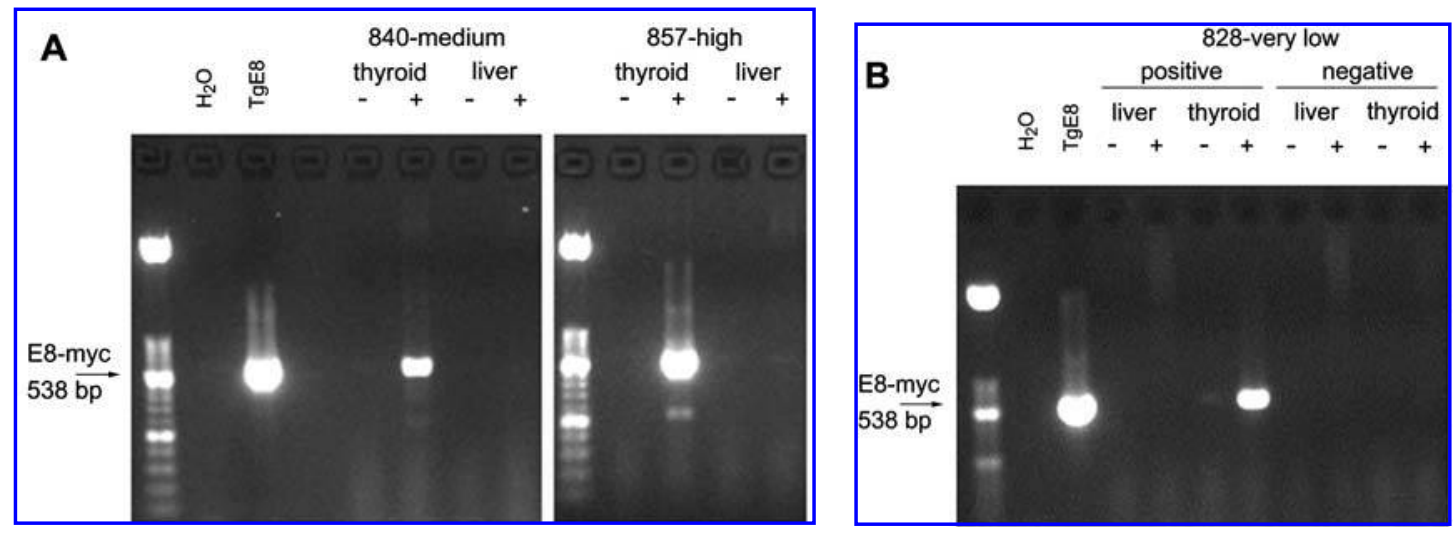

FIG. 5. Reverse transcriptase-polymerase chain reaction (RT-PCR) products from mouse thyroid and liver tissues obtained from mouse lines containing relatively high, medium (A) and very low (B) transgene copy number. A negative control of no cDNA and a positive control of Tg-FLIP (Tg-E8) plasmid were included in each set. RNA treated with RT (+) and without RT (-) are shown for each sample. RNA from a transgene negative littermate is also shown (B). 
amplified from RT reactions from thyroid RNA (Fig. 5). The same RNA from a RT reaction without enzyme did not produce a band, indicating that genomic DNA was not present or did not produce the band seen in these samples. FLIP message was clearly produced in thyroids from 8 out of the 12 lines, which were originally identified as positive for the transgene by PCR of tail DNA (numbers 811, 813, 826, 828, $833,840,842$, and 857). Message was detectable in all mice confirmed as positive for DNA by Southern blot, even in the lines demonstrating very low copy number.

\section{Detection of FLIP-Myc/His protein in thyroids of Tg-FLIP mice}

Western blot analyses detected Myc-tagged FLIP protein in the thyroids of some of the Tg-FLIP mRNA-positive mice (Fig. 6). In contrast, FLIP-myc/his was uniformly not expressed in the liver tissues of these mice, nor in transgene-negative animals (Fig. 5). FLIP-Myc/His protein was detected in thyroid samples from four FLIP-positive mouse lines (numbers 811,
826, 842, and 857). The level of FLIP-Myc/His expression differed between the mouse lines. Furthermore, the level of protein expression for each line was correlated to the relative copy number of the transgene identified by Southern blot. Tg-FLIP line 857 demonstrated the greatest amount of FLIP protein by Western blot and also the heaviest Tg-FLIP DNA bands by Southern blot. However, some mouse lines that had fewer copies of Tg-FLIP DNA while still producing detectable amounts of mRNA failed to produce detectable amounts of FLIP-Myc/His protein in the thyroid (numbers 828 and 833), suggesting that a certain number of Tg-FLIP DNA copies is necessary to generate sufficient amounts of FLIP protein detectable by Western blot.

\section{FLIP protein expression in the thyroid is not detrimental to} the development of mice or their thyroid glands

We observed Tg-FLIP transgenic mice for more than a year, and during this period these animals remained apparently healthy. Adult mice were able to breed and

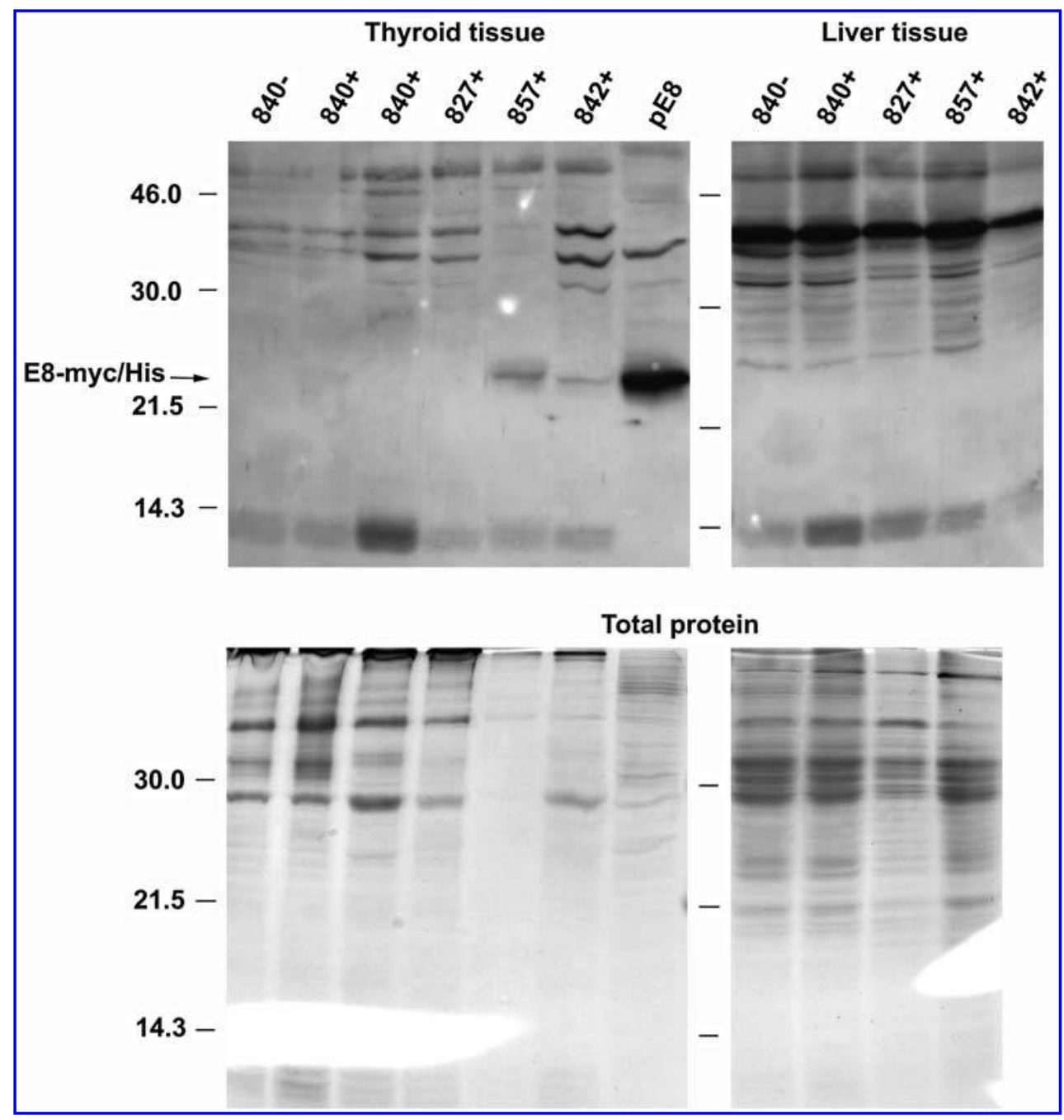

FIG. 6. Western blot of mouse tissue proteins detected FLIP-myc/his (E8-myc/his) using an anti-c-myc monoclonal antibody $(\mathrm{mAb})$. Thyroid and liver tissues from several positive and one negative mouse from different founder lines are shown. The expected size of the FLIP-myc/his protein is $22.8 \mathrm{kd}$, shown clearly in the lysate from an FLIP-expressing COS-1 transfectant (pFLIP) (pE8). 
showed no obvious differences in appearance and activity compared with their control littermates. Histologic examination on H\&E-stained sections of thyroids from transgenic animals obtained at various time points did not reveal any gross differences between transgenic mice and their gender- and age-matched control littermates (data not shown). In addition, no difference in thyroid morphology was observed.

\section{Discussion}

Our studies demonstrated that transgenic mice overexpressing FLIP in their thyrocytes had no thyroid or developmental abnormalities. The FLIP (E8) transgene has been previously transfected into multiple types of cells and documented to inhibit apoptosis induced by death receptors, such as CD95 and FLICE (14-6). In our study, FLIP expression on thyrocytes of transgenic mice was driven by the $\mathrm{Tg}$ promoter, which has been previously shown to specifically express target molecules in thyrocytes $(18,19)$. Using Southern blotting techniques we have clearly shown that the FLIP transgene was present in the thyrocytes of 8 transgenic lines (of a total of 12 generated), and it was not found in any thyroids of control mice. The expression of FLIP in thyrocytes from these transgenic mice was further confirmed at RNA and protein levels, as demonstrated by RT-PCR and Western blot analysis, respectively. To confirm that the FLIP molecule under the control of Tg was specifically expressed in the thyroid, we screened for FLIP mRNA and protein in nonthyroid tissues. The result demonstrated that the FLIP transgene was only expressed in thyroid tissue, documenting the specificity of the Tg promoter. Therefore, we created transgenic animal in which FLIP protein was specifically produced in thyrocytes.

Although some of the mouse lines with low copies of the FLIP transgene failed to produce detectable FLIP protein by Western blot, the transcription of the FLIP transgene was still demonstrable with RT-PCR. The reason for this is not entirely clear, however, there are several possible explanations. One of them is that the detection of mRNA with RT-PCR is more sensitive than detecting protein with Western blots. Another possible explanation is that low levels of protein may be related to the insertion sites in the genome or transelements that interfere with transcription and/or translation (20). This could also be the reason for the negative mRNA results in the 3 founder lines that produced transgene positive progeny as detected by PCR. Furthermore, it also is possible that post transcriptional modifications and/or mRNA degradation may also contribute to the low levels of FLIP protein below the threshold of Western blot in some of these animals.

Several studies have shown that FLIP can act not only as a tumor-progression factor $(21,22)$, but also as a contributing factor to the development of autoimmune disease (23). For example, FLIP expression has been shown to correlate with resistance against death receptor-induced apoptosis in B-cell lymphomas, and FLIP-transfected tumor cell lines develop more aggressive tumors in vivo $(21,22)$. Conversely, administering chemotherapeutic drugs to sensitized cells that are resistant to death receptor-induced apoptosis often correlates with decreased expression of FLIP (24). Several reports have also tied FLIP expression to thyroid diseases. Thyrocytes of
Graves disease have been reported to be associated with an increased FLIP level, which makes thyrocytes resistant to Fas-mediated apoptosis. It has been suggested that Fas-FLIP signaling in thyrocytes may stimulate the proliferation of thyrocytes in Graves disease (23). However, there also have been reports showing that FLIP fails to function as an antiapoptotic molecule in some cell death pathways (25-8). There is also a study indicating that binding of FLIP to FADD and caspase- 8 is insufficient to block apoptosis induced by the death receptors, suggesting that other mechanisms may be required (26). In our transgenic mice, FLIP apparently exerts neither antiapoptotic nor proapoptotic effects sufficient to change the phenotype of these animals. Significant lymphocyte infiltration or other evidence of inflammation was also not observed.

This report is the first to describe the thyroid-specific expression of FLIP in a transgenic mouse model. Our results demonstrate that the presence of FLIP in thyrocytes does not appear to interfere with the development of thyroid and induce thyroiditis in an unchallenging environment. It would be interesting to know whether expression of FLIP in thyrocytes would contribute to the pathogenesis of thyroiditis following insults, such as infection, radiation, or chemical administration.

In conclusion, transgenic mice with thyroid-specific expression of FLIP do not show apparent alterations in the development and dysfunction of the thyroid. Although these results show that FLIP-producing thyrocytes lack the pathologic features such as malignancy or autoimmunity, additional factors may be necessary for them to appear. Future studies where interventions such as the administration of autoantigen (TSHR, Tg, thyroid peroxidase) through various immunization protocols will make this transgenic model useful for better understanding how death pathways influence thyroid diseases.

\section{Acknowledgments}

We gratefully acknowledge Dr. C. Vincenz for the viral FLIP in pCDNA3.1 (-)/Myc-HisA plasmid; Dr. T.J. Giordano for help with histologic identification; and Mary E. Van Antwerp for help with manuscript preparation.

This work was supported by the National Institutes of Health Grants R01 A137141, P60DK20572, and DK58771.

\section{References}

1. Baker JR Jr 2001 The nature of apoptosis in the thyroid and the role it may play in autoimmune thyroid disease. Thyroid 11:245-247.

2. Wang SH, Bretz JD, Phelps E, Mezosi E, Arscott PL, Utsugi S, Baker JR Jr 2002 A unique combination of inflammatory cytokines enhances apoptosis of thyroid follicular cells and transforms nondestructive to destructive thyroiditis in experimental autoimmune thyroiditis. I Immunol 168:24702474.

3. Kreuz S, Siegmund D, Rumpf JJ, Samel D, Leverkus M, Janssen O, Hacker G, Dittrich-Breiholz O, Kracht M, Scheurich P, Wajant H 2004 NFkappaB activation by Fas is mediated through FADD, caspase-8, and RIP and is inhibited by FLIP. J Cell Biol 166:369-380.

4. Bannerman DD, Eiting KT, Winn RK, Harlan JM 2004 FLICElike inhibitory protein (FLIP) protects against apoptosis and 
suppresses NF-kappaB activation induced by bacterial lipopolysaccharide. Am J Pathol 165:1423-1431.

5. Catrina AI, Ulfgren AK, Lindblad S, Grondal L, Klareskog L 2002 Low levels of apoptosis and high FLIP expression in early rheumatoid arthritis synovium. Ann Rheum Dis 61:934-936.

6. Perlman H, Liu H, Georganas C, Koch AE, Shamiyeh E, Haines GK 3rd, Pope RM 2001 Differential expression pattern of the antiapoptotic proteins, Bcl-2 and FLIP, in experimental arthritis. Arthritis Rheum 44:2899-2908.

7. Wu W, Rinaldi L, Fortner KA, Russell JQ, Tschopp J, Irvin C, Budd RC 2004 Cellular FLIP long form-transgenic mice manifest a Th2 cytokine bias and enhanced allergic airway inflammation. J Immunol 172:4724-4732.

8. Wei Y, Chen K, Sharp GC, Braley-Mullen H 2003 FLIP and FasL expression by inflammatory cells vs. thyrocytes can be predictive of chronic inflammation or resolution of autoimmune thyroiditis. Clin Immunol 108:221-233.

9. Wei Y, Chen K, Sharp GC, Braley-Mullen H 2004 Fas ligand is required for resolution of granulomatous experimental autoimmune thyroiditis. I Immunol 173:7615-7621.

10. Tseveleki V, Bauer J, Taoufik E, Ruan C, Leondiadis L, Haralambous S, Lassmann H, Probert L 2004 Cellular FLIP (long isoform) overexpression in $\mathrm{T}$ cells drives Th2 effector responses and promotes immunoregulation in experimental autoimmune encephalomyelitis. I Immunol 173:6619-6626.

11. Djerbi M, Abdul-Majid KB, Abedi-Valugerdi, Olsson T, Harris RA, Grandien A 2003 Expression of the long form of human FLIP by retroviral gene transfer of hemopoietic stem cells exacerbates experimental autoimmune encephalomyelitis. I Immunol 170:2064-2073.

12. Semra YK, Seidi OA, Sharief MK 2001 Overexpression of the apoptosis inhibitor FLIP in T cells correlates with disease activity in multiple sclerosis. I Neuroimmunol 113:268-274.

13. Van Parijs L, Refaeli Y, Abbas AK, Baltimore D 1999 Autoimmunity as a consequence of retrovirus-mediated expression of C-FLIP in lymphocytes. Immunity 11:763-770.

14. OhYama T, Tsukumo S, Yajima N, Sakamaki K, Yonehara S 2000 Reduction of thymocyte numbers in transgenic mice expressing viral FLICE-inhibitory protein in a Fas-independent manner. Microbiol Immunol 44:289-297.

15. Wu Z, Roberts M, Porter M, Walker F, Wherry EJ, Kelly J, Gadina M, Silva EM, DosReis GA, Lopes MF, O'Shea J, Leonard WJ, Ahmed R, Siegel RM Viral FLIP impairs survival of activated $\mathrm{T}$ cells and generation of CD8 $+\mathrm{T}$ cell memory. J Immunol 172:6313-6323.

16. Hu S, Vincenz C, Buller M, Dixit VM 1997 A novel family of viral death effector domain-containing molecules that inhibit both CD-95- and tumor necrosis factor receptor-1-induced apoptosis. I Biol Chem 272:9621-9624.

17. Musti AM, Ursini VM, Avvedimento EV, Zimarino V, Di Lauro R 1987 A cell type specific factor recognizes the rat thyroglobulin promoter. Nucl Acids Res 15:8149-8166.

18. Shimura H, Suzuki H, Miyazaki A, Furuya F, Ohta K, Haraguchi K, Endo T, Onaya T 2001 Transcriptional activa- tion of the thyroglobulin promoter directing suicide gene expression by thyroid transcription factor- 1 in thyroid cancer cells. Cancer Res 61:3640-3646.

19. Zhang R, Straus FH, DeGroot LJ 2001 Adenoviral-mediated gene therapy for thyroid carcinoma using thymidine kinase controlled by thyroglobulin promoter demonstrates high specificity and low toxicity. Thyroid 11:115-123.

20. Scicchitano DA, Olesnicky EC, Dimitri A 2004 Transcription and DNA adducts: what happens when the message gets cut off? DNA Repair 3:1537-1548.

21. Igney FH, Krammer PH 2002 Death and anti-death: Tumour resistance to apoptosis. Nat Rev Cancer 2:277-288.

22. Thome M, Tschopp J 2001 Regulation of lymphocyte proliferation and death by FLIP. Nat Rev Immunol 1:50-58.

23. Stassi G, Di Liberto D, Todaro M, Zeuner A, Ricci-Vitiani L, Stoppacciaro A, Ruco L, Farina F, Zummo G, De Maria R 2000 Control of target cell survival in thyroid autoimmunity by $\mathrm{T}$ helper cytokines via regulation of apoptotic proteins. Nat Immunol 1:483-488.

24. Wajant H 2003 Targeting the FLICE Inhibitory Protein (FLIP) in cancer therapy. Mol Interv 3:124-127.

25. Chang DW, Xing Z, Pan Y, Algeciras-Schimnich A, Barnhart BC, Yaish-Ohad S, Peter ME, Yang X 2002 c-FLIP(L) is a dual function regulator for caspase-8 activation and CD95-mediated apoptosis. EMBO J 21:3704-3714.

26. Garvey TL, Bertin J, Siegel RM, Wang GH, Lenardo MJ, Cohen JI 2002 Binding of FADD and caspase-8 to molluscum contagiosum virus MC159 v-FLIP is not sufficient for its antiapoptotic function. J Virol 76:697-706.

27. Kataoka T, Schroter M, Hahne M, Schneider P, Irmler M, Thome M, Froelich CJ, Tschopp J 1998 FLIP prevents apoptosis induced by death receptors but not by perforin/ granzyme B, chemotherapeutic drugs, and gamma irradiation. J Immunol 161:3936-3942.

28. Youn BS, Kim YJ, Mantel C, Yu KY, Broxmeyer HE 2001 Blocking of c-FLIP(L)-independent cycloheximide-induced apoptosis or Fas-mediated apoptosis by the CC chemokine receptor 9/TECK interaction. Blood 98:925-933.

29. Oehme I, Neumann F, Bosser S, Zornig M 2005 Transgenic overexpression of the Caspase- 8 inhibitor FLIP(short) leads to impaired $\mathrm{T}$ cell proliferation and an increased memory $\mathrm{T}$ cell pool after staphylococcal enterotoxin B injection. Eur J Immunol 35:1240-1249.

Address reprint requests to: Dr. James R. Baker, Jr. Department of Medicine University of Michigan Medical Center 9220 MSRB III Ann Arbor MI 48109-0648

E-mail: jbakerjr@umich.edu 


\section{This article has been cited by:}

1. Milovan D. Matovic, Slobodan M. Jankovic, Marija Jeremic, Zoran Tasic, Marina Vlajkovic . Unexpected Effect of Furosemide on Radioiodine Urinary Excretion in Patients with Differentiated Thyroid Carcinomas Treated with 131IUnexpected Effect of Furosemide on Radioiodine Urinary Excretion in Patients with Differentiated Thyroid Carcinomas Treated with 131I. Thyroid, ahead of print. [Abstract] [PDF] [PDF Plus]

2. Rocco Bruno, Paolo Giannasio, Rosarita Chiarella, Carmelo Capula, Diego Russo, Sebastiano Filetti, Giuseppe Costante . 2009. Identification of a Neck Lump as a Lymph Node Metastasis from an Occult Contralateral Papillary Microcarcinoma of the Thyroid: Key Role of Thyroglobulin Assay in the Fine-Needle AspirateIdentification of a Neck Lump as a Lymph Node Metastasis from an Occult Contralateral Papillary Microcarcinoma of the Thyroid: Key Role of Thyroglobulin Assay in the Fine-Needle Aspirate. Thyroid 19:5, 531-533. [Abstract] [PDF] [PDF Plus]

3. Monica G. Cardenas, Sudha Kini , Max Wisgerhof . 2009. Two Patients with Highly Aggressive Macrofollicular Variant of Papillary Thyroid CarcinomaTwo Patients with Highly Aggressive Macrofollicular Variant of Papillary Thyroid Carcinoma. Thyroid 19:4, 413-416. [Abstract] [PDF] [PDF Plus]

4. William C. Faquin. 2009. Diagnosis and Reporting of Follicular-Patterned Thyroid Lesions by Fine Needle Aspiration. Head and Neck Pathology 3:1, 82-85. [CrossRef]

5. Se Jeong Jeon, Eunhee Kim, Jeong Seon Park, Kyu Ri Son, Jung Hwan Baek, Yoon Suk Kim, Do Joon Park, Bo Youn Cho, Dong Gyu Na. 2009. Diagnostic Benefit of Thyroglobulin Measurement in Fine-Needle Aspiration for Diagnosing Metastatic Cervical Lymph Nodes from Papillary Thyroid Cancer: Correlations with US Features. Korean Journal of Radiology 10:2, 106. [CrossRef]

6. Yasuhiro ITO, Akira MIYAUCHI. 2009. Prognostic Factors and Therapeutic Strategies for Differentiated Carcinomas of the Thyroid. Endocrine Journal 56:2, 177-192. [CrossRef]

7. Simon Grodski, Leigh Delbridge. 2009. An update on papillary microcarcinoma. Current Opinion in Oncology 21:1, 1-4. [CrossRef]

8. H Carter Davidson, Brian J. Park, Jonas T. Johnson. 2009. Papillary Thyroid Cancer: Controversies in the Management of Neck Metastasis. The Laryngoscope 118:12, 2161-2165. [CrossRef]

9. Iwao Sugitani, Yoshihide Fujimoto, Keiko Yamada, Noriko Yamamoto. 2008. Prospective Outcomes of Selective Lymph Node Dissection for Papillary Thyroid Carcinoma Based on Preoperative Ultrasonography. World Journal of Surgery 32:11, 2494-2502. [CrossRef]

10. Umberto Crocetti, Cosimo Durante, Marco Attard, Adele Maniglia, Salvatore Tumino , Rocco Bruno, Nazario Bonfitto , Franca Dicembrino, Antonio Varraso, Domenico Meringolo, Sebastiano Filetti, Vincenzo Trischitta , Massimo Torlontano . 2008. Predictive Value of Recombinant Human TSH Stimulation and Neck Ultrasonography in Differentiated Thyroid Cancer PatientsPredictive Value of Recombinant Human TSH Stimulation and Neck Ultrasonography in Differentiated Thyroid Cancer Patients. Thyroid 18:10, 1049-1053. [Abstract] [PDF] [PDF Plus]

11. N. Palestini, A. Borasi, L. Cestino, M. Freddi, C. Odasso, A. Robecchi. 2008. Is central neck dissection a safe procedure in the treatment of papillary thyroid cancer? Our experience. Langenbeck's Archives of Surgery 393:5, 693-698. [CrossRef]

12. Nia D. Banks, Jeanne Kowalski, Hua-Ling Tsai, Helina Somervell, Ralph Tufano, Alan P.B. Dackiw , Michael R. Marohn , Douglas P. Clark, Christopher B. Umbricht, Martha A. Zeiger . 2008. A Diagnostic Predictor Model for Indeterminate or Suspicious Thyroid FNA SamplesA Diagnostic Predictor Model for Indeterminate or Suspicious Thyroid FNA Samples. Thyroid 18:9, 933-941. [Abstract] [PDF] [PDF Plus]

13. Jenny Gough, David Scott-Coombes, F. Fausto Palazzo. 2008. Thyroid Incidentaloma: An Evidence-based Assessment of Management Strategy. World Journal of Surgery 32:7, 1264-1268. [CrossRef]

14. Lilah F. Morris, Nagesh Ragavendra, Michael W. Yeh. 2008. Evidence-Based Assessment of the Role of Ultrasonography in the Management of Benign Thyroid Nodules. World Journal of Surgery 32:7, 1253-1263. [CrossRef]

15. Edmund S. Cibas, Erik K. Alexander, Carol B. Benson, Pedro Patricio de Agustín, Gerard M. Doherty, William C. Faquin, William D. Middleton, Theodore Miller, Stephen S. Raab, Matthew L. White, Susan J. Mandel. 2008. Indications for thyroid FNA and pre-FNA requirements: A synopsis of the National Cancer Institute Thyroid Fine-Needle Aspiration State of the Science Conference. Diagnostic Cytopathology 36:6, 390-399. [CrossRef]

16. Andrea Abati. 2008. The National Cancer Institute Thyroid FNA State of the Science Conference: "Wrapped up". Diagnostic Cytopathology 36:6, 388-389. [CrossRef]

17. Kathryn G. Schuff, Stephen M. Weber, Babak Givi, Mary H. Samuels, Peter E. Andersen, James I. Cohen. 2008. Efficacy of Nodal Dissection for Treatment of Persistent/Recurrent Papillary Thyroid Cancer. The Laryngoscope 118:5, 768-775. [CrossRef] 
18. Edmund S. Cibas, Miguel A. Sanchez. 2008. The National Cancer Institute Thyroid Fine-Needle Aspiration State-of-the-Science Conference. Cancer 114:2, 71-73. [CrossRef]

19. Robert Udelsman. 2008. Is total thyroidectomy the procedure of choice for papillary thyroid cancer?. Nature Clinical Practice Oncology 5:4, 184-185. [CrossRef]

20. A. Van den Bruel, R. Moreno-Reyes, M. Bex, C. Daumerie, D. Glinoer. 2008. Is the management of thyroid nodules and differentiated thyroid cancer in accordance with recent consensus guidelines? - Results of a national survey. Clinical Endocrinology 68:4, 599-604. [CrossRef]

21. Mulazim Hussain Bukhari, Shahida Niazi, Ghazala Hanif, Shahzad Shafqat Qureshi, Mohammad Munir, Mumtaz Hasan, Samina Naeem. 2008. An updated audit of fine needle aspiration cytology procedure of solitary thyroid nodule. Diagnostic Cytopathology 36:2, 104-112. [CrossRef]

22. Annick Van den Bruel, Philip Roelandt, Maria Drijkoningen, Jean-Pierre Hudders, Brigitte Decallonne, Roger Bouillon . 2008. A Thyroid Thriller: Acute Transient and Symmetric Goiter after Fine-Needle Aspiration of a Solitary Thyroid NoduleA Thyroid Thriller: Acute Transient and Symmetric Goiter after Fine-Needle Aspiration of a Solitary Thyroid Nodule. Thyroid 18:1, 81-84. [Abstract] [PDF] [PDF Plus]

23. Mehmet Ali Gulcelik, Nese Ersoz Gulcelik, Bekir Kuru, Mithat Camlibel, Haluk Alagol. 2008. Prognostic factors determining survival in differentiated thyroid cancer. Journal of Surgical Oncology 96:7, 598-604. [CrossRef]

24. Yasuhiro Ito, Nobuyuki Amino, Tamotsu Yokozawa, Hisashi Ota, Maki Ohshita, Nao Murata, Shinji Morita, Kaoru Kobayashi , Akira Miyauchi . 2007. Ultrasonographic Evaluation of Thyroid Nodules in 900 Patients: Comparison Among Ultrasonographic, Cytological, and Histological FindingsUltrasonographic Evaluation of Thyroid Nodules in 900 Patients: Comparison Among Ultrasonographic, Cytological, and Histological Findings. Thyroid 17:12, 1269-1276. [Abstract] [PDF] [PDF Plus]

25. Su He Wang , James R. Baker , Jr. . 2007. The Role of Apoptosis in Thyroid AutoimmunityThe Role of Apoptosis in Thyroid Autoimmunity. Thyroid 17:10, 975-979. [Abstract] [PDF] [PDF Plus]

26. Martin Schlumberger, Marcel Ricard, Gérard De Pouvourville, Furio Pacini. 2007. How the availability of recombinant human TSH has changed the management of patients who have thyroid cancer. Nature Clinical Practice Endocrinology \& \#\#38; Metabolism 3:9, 641-650. [CrossRef]

27. Martin Schlumberger, Ludovic Lacroix, Diego Russo, Sebastiano Filetti, Jean-Michel Bidart. 2007. Defects in iodide metabolism in thyroid cancer and implications for the follow-up and treatment of patients. Nature Clinical Practice Endocrinology \& \#38; Metabolism 3:3, 260-269. [CrossRef]

28. Kiichiroh NAKANO, Akira TANGOKU. 2007. LIVER AND BONE METASTASIS OF PAPILLARY CARCINOMA OF THYROID THAT RESPONDED WELL TO I-131 ADMINISTRATION. Nibon Rinsho Geka Gakkai Zasshi (Journal ofJapan Surgical Association) 68:8, 1908-1913. [CrossRef]

29. Martin Schlumberger, Isabelle Borget, G\&eacute;rard De Pouvourville, Furio Pacini. 2007. Recombinant Human Thyroid-Stimulating Hormone: Use in Papillary and Follicular Thyroid Cancer. Hormone Researcb 67:1, 132-142. [CrossRef]

30. Jack M. Monchik, Ronald A. DeLellis. 2007. Re-operative neck surgery for well-differentiated thyroid cancer of follicular origin. Journal of Surgical Oncology 94:8, 714-718. [CrossRef]

31. Yolanda C. Oertel . 2007. Cytopathology Reports from Fine Needle Aspirations of the Thyroid Gland: Can They Be Improved?Cytopathology Reports from Fine Needle Aspirations of the Thyroid Gland: Can They Be Improved?. Thyroid 17:1, 33-35. [Abstract] [PDF] [PDF Plus]

32. 2006. Letters to the EditorLetters to the Editor. Thyroid 16:12, 1323-1327. [Citation] [PDF] [PDF Plus]

33. Barbara D. Florentine, Barry Staymates, Munif Rabadi, Nayibe Sarda, John Barstis, Alexander Black. 2006. Cost savings associated with the use of fine-needle aspiration biopsy (FNAB) for the diagnosis of palpable masses in a community hospital-based FNAB clinic. Cancer 107:9, 2270-2281. [CrossRef]

34. Tae Yong Kim, Won Bae Kim, Yoon Soo Rhee, Ja Young Song, Jung Min Kim, Gyungyub Gong, Seungkoo Lee, Sang Yoon Kim, Seong Chul Kim, Suck Joon Hong, Young Kee Shong. 2006. The BRAF mutation is useful for prediction of clinical recurrence in low-risk patients with conventional papillary thyroid carcinoma. Clinical Endocrinology 65:3, 364-368. [CrossRef]

35. A Carpi, A G Naccarato, G Iervasi, A Nicolini, G Bevilacqua, P Viacava, P Collecchi, L Lavra, C Marchetti, S Sciacchitano, A Bartolazzi. 2006. Large needle aspiration biopsy and galectin-3 determination in selected thyroid nodules with indeterminate FNA-cytology. British Journal of Cancer 95:2, 204-209. [CrossRef]

36. Brian J. Yoder, Rachel Redman, Nicole A. Massoll . 2006. Validation of a Five-Tier Cytodiagnostic System for Thyroid Fine Needle Aspiration Biopsies Using Cytohistologic CorrelationValidation of a Five-Tier Cytodiagnostic System for Thyroid Fine Needle Aspiration Biopsies Using Cytohistologic Correlation. Thyroid 16:8, 781-786. [Abstract] [PDF] [PDF Plus] 
37. Sebastiano Filetti, Cosimo Durante, Massimo Torlontano. 2006. Nonsurgical approaches to the management of thyroid nodules. Nature Clinical Practice Endocrinology \& \#38; Metabolism 2:7, 384-394. [CrossRef] 